\title{
Yedi-24 Aylık Bebeği Olan Annelerin Tamamlayıcı Beslenmeye ilişkin Bilgi ve Uygulamaları: Hastane Tabanlı Bir Araştırma*
}

\section{The Knowledge and Practices of Mothers with 7-24 Month-Old Babies on Complementary Feeding: A Hospital-Based Research}

\section{Beyza Uçar ${ }^{1}$ (D) Özlem Öztürk Şahin² (D)}

${ }^{1}$ Karabük Üniversitesi, Sağlık Hizmetleri Meslek Yüksekokulu, Tıbbi Hizmetler ve Teknikler Bölümü, Tıbbi Laboratuvar Teknikleri Programı, Karabük, Türkiye ${ }^{2}$ Karabük Üniversitesi, Sağlık Bilimleri Fakültesi, Hemşirelik Bölümü, Çocuk Sağlığı ve Hastalıkları Hemşireliği Anabilim Dalı, Karabük, Türkiye

ORCID ID: B.U. 0000-0001-8596-6936; 0̈.0̈.Ş. 0000-0001-8781-3706

Atıf/Citation: Ucar B, Ozturk Sahin O. Yedi-24 aylık bebeği olan annelerin tamamlayıcı beslenmeye ilişkin bilgi ve uygulamaları: Hastane tabanlı bir araştırma. Çocuk Dergisi - Journal of Child 2021;21(1):48-55. https://doi.org/10.26650/jchild.2021.1.788576

öz

Amaç: Yedi-24 aylık bebeği olan annelerin tamamlayıcı beslenme konusundaki bilgi durumları ve uygulamalarını belirlemek amacı ile yapıldı. Gereç ve Yöntem: Tanımlayıcı ve kesitsel tipte bir çalışmadır. Çalışma, Karabük Üniversitesi Eğitim ve Araştırma Hastanesi çocuk polikliniklerine, 7-24 aylık bebeği olup 15 Şubat-15 Mayıs 2019 tarihleri arasında başvuru yapan 380 anne ile gerçekleştirildi. Araştırmada veri toplama aracı olarak, dört bölümden oluşan ve 35 soru içeren anket formu kullanıldı.

Bulgular: Annelerin $\% 75,8^{\prime} i$ emzirme ve tamamlayıc beslenme ile ilgili bilgi aldığını ifade ederken, bilgi edinilen kaynaklarda \%38 ile "hemşire/ ebe"nin ilk sırada yer aldığı görüldü. Annelerin \%99,5'i tamamlayıcı besin vermeye geçtiklerini belirtirken, bu annelerin verdikleri tamamlayıcı besinde $\% 47,9$ ile yoğurdun ilk tercih edilen besin olduğu görüldü. Annelerin bebeklerinde tamamlayıcı beslenmede bazı uygulamaların süre ortalaması incelendiğinde; tamamlayıcı beslenmeye başlama zamanı $(5,48 \pm 2,09)$, su verme zamanı $(3,95 \pm 2,52)$, çatal-kaşık kullanılma zamanı $(6,27 \pm 1,88)$ ve katı ve pürtüklü gıdaya başlanma zamanı $(7,02 \pm 1,84)$ ay olarak belirlendi. Annenin eğitim durumu $(p=0,000)$, biberon kullanımı $(p=0,000)$, emzik kullanımı ( $p=0,001)$, formül mama $(p=0,000)$ ve kaşık mama kullanımı $(p=0,005)$ ile tamamlayıcı beslenmeye başlama zamanı arasında istatistiksel olarak anlamlı fark bulunmaktaydı.

Sonuç: Çalışmadan elde edilen bulgular, annelerin tamamlayııı beslenme konusundaki bilgi durumlarının yeterli olmadığını, tamamlayıcı beslenme sürecini olumsuz etkileyebilecek bazı yanlış uygulamaları olduğunu göstermektedir. Annelerin biberon, emzik, formül ve kaşık mama kullanımının tamamlayıcı beslenmeye geçiş sürecini ise olumsuz etkilediği sonucuna varıldı.

Anahtar Kelimeler: Anne, bebek, emzirme, tamamlayıcı beslenme

\section{ABSTRACT}

Objective: This study aims to determine the knowledge status and practices of mothers with babies aged 7-24 months about complementary feeding.

Method: This is a descriptive and cross-sectional study. The study was conducted with 380 mothers who had 7-24 months old babies and were referred to the pediatric outpatient clinics of Karabük University Training and Research Hospital between 15 February and 15 May 2019. A questionnaire form consisting of four parts and containing 35 questions was used as a data collection tool in the study.

Results: It was found that $75.8 \%$ of the mothers received information about breastfeeding and complementary feeding, where "nurse/midwife" (38\%) ranked first among their information sources. $99.5 \%$ of the mothers started complementary feeding, where yoghurt $(47.9 \%)$ ranked first among the foods they preferred for complementary feeding. When the average duration of some complementary feeding practices of mothers was examined; the mean times to start complementary feeding, to give water, to use a fork-spoon and to start solid and rough food were found as $5.48 \pm 2.09,3.95 \pm 2.52,6.27 \pm 1.88$, and $7.02 \pm 1.84$ months, respectively. A statistically significant difference was determined between the mothers' times to start complementary feeding with respect to their education level $(p=0.000)$, use of feeding bottles $(p=0.000)$, use of pacifiers $(p=0.001)$, use of baby food ( $p=0.000)$ and use of spoon food ( $p=0.005$ ).

Conclusion: This study demonstrated that mothers did not have sufficient knowledge about complementary feeding, and adopted some wrong practices that might negatively affect the complementary feeding process. The study concluded that the use of feeding bottles, pacifiers, baby food and spoon formula by mothers for their babies negatively affected the transition to complementary feeding.

Keywords: Baby, breastfeeding, complementary feeding, mother

*Bu çalışma, "7-24 ay arası bebeği olan annelerin tamamlayıcı beslenme konusundaki bilgi durumları ve uygulamaları" başlıklı yüksek lisans tezinden türetilmiştir.

Sorumlu Yazar/Corresponding Author: Özlem Öztürk Şahin E-mail: zlemzturk@hotmail.com

Başvuru/Submitted: 01.09.2020 • Revizyon Talebi/Revision Requested: 30.12.2020 • Son Revizyon/Last Revision Received: 10.01.2021 • Kabul/Accepted: 01.02.2021 


\section{GiRiş}

Anne sütü, $D$ ve $K$ vitaminleri haricinde bebeğin tüm enerji ve besin ihtiyaçlarını ilk altı ay tek başına karşılayan mükemmel bir besindir (1). Ancak, altıncı aydan sonra içerik olarak bebeğin beslenmesinde tek başına yetersiz kalmakta ve bu nedenle tamamlayıcı besin ile beslenmenin desteklenmesi önerilmektedir (2). Anne sütüne ek olarak besinlerin verilmesine tamamlayıcı besin, bu sürece de tamamlayıcı beslenme denir (3).

Tamamlayıc beslenme süreci, bebeğin aile besinlerine geçişinde önemli bir basamaktır ve doğru yürütülmediğinde bebeğin ileriki yaşamında gıda kabulünü etkilemekte veya beslenme problemlerine yol açabilmektedir (4). Tamamlayıcı beslenme uygulamaları bebeklerde optimal büyümeyi sağlamak için önemliyken, uygunsuz tamamlayıcı beslenme uygulamaları ise bebeklerde ve çocuklarda hastalık ve ölüm riskini artırır $(5,6)$. Altıncı aydan sonra başlanılması önerilen tamamlayıcı beslenmeye erken ya da geç başlanılması, bebek ve çocuk sağığını olumsuz etkilemektedir (7). Ayrıca, bebeğin büyümesinin gecikmesinde en önemli nedenler arasında yer almaktadır (8).

Tamamlayıcı besinler ile erken karşılaşma, alerji ve enfeksiyon riskini arttrabilir. Ayrıca, tamamlayıcı beslenmeye erken geçilmesinin emzirme süresini azalttğı bilinmektedir (9). Oysaki, Dünya Sağıık Örgütü (DSÖ) ve Birleşmiş Milletler Çocuklara Yardım Fonu [United Nations International Children's Emergency Fund (UNICEF)] bebeklerin doğumdan itibaren ilk alth ay sadece anne sütü ile beslenmesini ve altıncı aydan sonra ek gıdalar verilmesinin yanında, emzirmeye iki yaşına kadar devam edilmesini önermektedir (10). Ancak, dünyada ilk alt ay sadece anne sütü alma ve emzirmeye devam etme süresi henüz istenilen düzeyde değildir. Gelişmekte olan ülkelerde alt aydan küçük bebeklerin sadece \%39'u anne sütü almaktadır (11). Türkiye Nüfus Sağlık Araştırması (TNSA) (2018) raporuna göre de, anne sütü alımının bebeğin yaşı arttıkça azalmakta olduğu 4. ve 5. aylarda anne sütü alan bebek oranın \%14'e kadar düştüğü bildirilmektedir (12).

Tamamlayıc beslenmeye geç başlanması ise, bebeğin yeterli enerji ve besin öğelerini alamamasına, dolayısıyla büyüme ve gelişmeyi yavaşlatmakta hatta malnütrisyona neden olabilmektedir (11). Bazı besinlerin geç tanıtılması, çiğneme becerisi kazanamamasına, yeni tat ve duyu kaybı yaşama gibi beslenme problemlerine neden olabilir. Çünkü tamamlayıcı beslenme, bebeğe hem lezzet hem de değişik besinler için benzersiz bir duyusal deneyim de sunar $(13,14)$.

Tamamlayıcı beslenme uygulamalarında, tamamlayıcı besinlere geç veya erken başlama ve anne sütünden erken kesme eğilimi nedeniyle, annelerin doğum öncesi ve sonrası eğitim programları ile bilinçlendirilmesi konusunda sağlık profesyonellerine özellikle hemşirelere önemli görevler düşmektedir. Hemşirelerin anne sütü ve tamamlayıcı beslenme konusunda danışmanlık sağlamaları, çocuk sağlığının korunması ve geliştirilmesi açısından önemli yere sahiptir $(15,16)$. Bu nedenle annelere yönelik eğitimlerin planlanması açısından; doğru ve uygun tamamlayıc beslenme uygulamalarının anneler tarafindan bilinip bilinmediğinin ve anneler tarafindan yapılan tamamlayıcı beslenme uygulamalarındaki yanlışlıkların tespit edilmesi, literatüre önemli bir katkı sağlayacaktır. Bu bağlamda çalışma, 7-24 aylık bebeği olan annelerin tamamlayıcı beslenme konusundaki bilgi durumları ve uygulamalarını belirlemek amacı ile yapıldı.

\section{Araşttrma soruları;}

- Annelerin tamamlayıcı beslenme konusundaki bilgi durumları nasıldır?

- Annelerin tamamlayıcı beslenme konusundaki uygulamaları nasıldır?

- Annelere ve bebeklere ait bazı tanımlayıcı özelliklerin, annelerin tamamlayıcı beslenme konusundaki bilgi durumlarına ve uygulamalarına etkisi nasıldır?

\section{GEREÇ VE YÖNTEM}

\section{Araştırmanın tipi}

Tanımlayıcı ve kesitsel tipte bir çalışmadır.

\section{Araştırmanın yeri}

Araştırma, Türkiye Cumhuriyeti Sağlık Bakanlığı Karabük Üniversitesi Eğitim ve Araştırma Hastanesinde, 15 Şubat-15 Mayıs 2019 tarihleri arasında gerçekleştirildi. Çalışmanın yürütüldüğü hastane, ayaktan ve yataklı olarak tedavi hizmeti sunan, Karabük'teki tek eğitim ve araştırma hastanesidir. Hastanede alt (6) çocuk polikliniği hizmet vermekte olup, bu polikliniklerin hepsi çalışmaya dahil edildi.

\section{Araştırmanın evreni ve örneklemi}

Araştırmanın evrenini, Karabük Üniversitesi Eğitim ve Araştırma Hastanesi çocuk polikliniklerine, 7-24 aylık bebeği olup çalışmanın yürütüldüğü tarihler arasında başvuru yapan anneler oluşturdu. Kurumun istatistik birimi ile görüşülmüş olup, alt çocuk polikliniğine bir yıl içinde 7-24 aylık 7503 bebeğin başvurusunun yapıldığı belirlendi. Evreni bilinen örneklem formülü ile \%95 güven aralığında ve $\% 5$ hata payı ile ulaşılması gereken en az sayı 366 olarak hesaplandı. Çalışmada, veri kayıpları olabileceği varsayılarak 380 bebeğin annesi örnekleme dahil edildi. Bebeklerin annelerinin çalışmaya dahil edilme kriterleri ise, bebeğin yanında refakat eden ebeveynin anne olması, annenin yaşının 18 yaş ve üstü olması, Türkçe konuşabilmesi ve Türkçe okuryazarlığının olması ve çalışmaya katılmaya gönüllü olmasıydı.

\section{Veri toplama aracı}

Anket Formu: Araştırmacılar tarafindan hazırlanan bu form dört bölümden oluşmak üzere toplam 35 soru içermekteydi. Bu bölümler; 1 . annelere ait tanımlayıc özellikler, 2. bebeklere ait tanımlayıcı özellikler, 3 . annelerin anne sütü ve emzirme ile ilgili özellikleri, 4. annelerin tamamlayıcı beslenme konusunda bilgi durumları ve uygulamaları.

\section{Veri toplama aracının uygulanması}

Araştırma verileri, örneklemi oluşturan 380 anneden toplandı. Veri toplama formu, araştırmacılar tarafindan yüz yüze görüşme yoluyla toplandı. Formda yer alan sorular annelere araştırmacılar tarafindan yöneltilerek annelerin yanıtlamaları sağlandı. Formun uygulanması her bir anne için ortalama 10-15 dakika sürdü. 


\section{İstatistiksel analiz}

Verilerin istatiksel değerlendirilmesinde IBM SPSS Statistics 23 programı kullanıldı. Çalışma verileri değerlendirilirken kategorik değişkenler için frekans dağılımı (sayı, yüzde), sayısal değişkenler için tanımlayıcı istatistikler (ortalama, standart sapma) verildi. İki gruba sahip kategorik değişkenler arasındaki farkın incelenmesinde bağımsız örneklem t testinden, ikiden fazla gruba sahip kategorik değişkenler arasındaki farkın incelenmesinde ise "tek yönlü varyans analizi" (ANOVA) ile test edildi. Analiz sonucunda öncelikle varyans homojenliği için Levene testine, ardından farklıı̆ı̆ hangi grup ya da gruplardan kaynaklandığı "çoklu karşılaştırma testi" (Bonferonni ya da Tamhane's T2) ile kontrol edildi. Varyans homojenliğini sağlayan değişkenlerde gruplar arasındaki fark incelemesi için Bonferonni, varyans homojenliğini sağlamayan değişkenlerde gruplar arasında fark

Tablo 1: Annelere ve bebeklere ait tanımlayıcı özellikler.

\begin{tabular}{|c|c|}
\hline Özellikler & Ort $\pm S S$ \\
\hline Annelerin yaş ortalaması (yıl) & $30,42 \pm 5,51$ \\
\hline \multirow[t]{2}{*}{ Bebeklerin yaş ortalaması (ay) } & $14,92 \pm 5,16$ \\
\hline & $\mathbf{n}$ \\
\hline
\end{tabular}

Annelerin eğitim durumu $(n=380)$

$\begin{array}{lcc}\text { Sadece okuryazar } & 10 & 2,6 \\ \text { İlkokul } & 80 & 2,0 \\ \text { Ortaokul } & 69 & 18,2 \\ \text { Lise } & 120 & 31,6 \\ \text { Üniversite ve üzeri } & 101 & 26,6 \\ \text { Annelerin çalışma durumu (n=380) } & & \\ \text { Çalışıyor } & 56 & 14,7 \\ \text { Çalışmıyor } & 324 & 85,3 \\ \text { Annelerin meslek dağılımı (n=56) } & & * \\ \text { Serbest meslek } & 10 & 17,9 \\ \text { İşçi } & 10 & 17,9 \\ \text { Memur } & 17 & 30,3 \\ \text { Sağlık çalışanı } & 19 & 33,9\end{array}$

Annelerin bebeklerini bir süre emzirme durumu $(n=380)$

$\begin{array}{lcc}\text { Evet } & 377 & 99,2 \\ \text { Hayır } & 3 & 0,8 \\ \text { Anelerin bebeklerini ay olarak emzirme } & & * * *\end{array}$
durumları $(\mathrm{n}=377)^{* *}$

$\begin{array}{lcc}\text { 4 aydan az emziren } & 33 & 8,8 \\ \text { 4-6 ay arası emziren } & 24 & 6,4 \\ \text { Emzirmekte olan (ort:13,64 ay) } & 239 & 63,4 \\ \text { en az:7 ay, en çok:24 ay) } & & \\ \begin{array}{l}\text { Şu anda emzirmeyen (ort:11,28 ay) } \\ \text { (en az:0 ay, en çok:23 ay) }\end{array} & 81 & 21,4\end{array}$

\begin{tabular}{lc} 
& Ort \pm SS \\
\hline $\begin{array}{l}\text { Bebeklerin sadece anne sütü alma süresi (ay) } \\
\text { (n=377) }\end{array}$ & $4,56 \pm 1,95$ \\
\hline
\end{tabular}

Ort: ortalama, SS: standart sapma

*: \% değerleri çalışan anne sayısı 56'ya göre hesaplandı.

**: Bebeğini emzirmeyen 3 kişi analiz dışı bırakıldı.

***: \% değerleri 377'e göre hesaplandı. incelemesi için Tamhane's T2 testine bakıldı. Ayrıca iki sayısal değişken arasındaki ilişkinin incelenmesinde korelasyon analizinden, iki kategorik değişken arasındaki ilişkinin incelenmesinde ise ki kare testinden yararlanıldı. Sonuçlar \%95 güven aralığında değerlendirildi ve $p<0.05$ değeri anlamlı kabul edildi.

\section{Araştırmanın etik yönü}

Çalışmanın gerçekleştirilmesi için Karabük Üniversitesi Girişimsel Olmayan Etik Kurulundan etik kurul onayı (Tarih: 05.02.2019, Protokol Numarası: 77192459-050.99-E.5689) ve Karabük Üniversitesi Eğitim ve Araştirma Hastanesinden (Tarih: 07.02.2019, Protokol Numarası: 34771223-774.99) kurum izni alındı. Çalışma kapsamındaki annelere araştırma hakkında bilgi verilerek, gönüllük ilkesi ön planda tutuldu. Çalışmaya katılmayı kabul eden annelerin sözlü ve yazılı onamları alındı.

\section{BULGULAR}

Çalışmaya katılan annelerin yaş ortalaması 30,42 yıl, bebeklerin yaş ortalaması ise 14,92 aydı. Annelerin $\% 31,6$ 'sı lise mezunuyken, \%85,3'ü herhangi bir işte çalışmıyordu. Annelerin \%99,2 gibi büyük bir çoğunluğu bebeğini bir süre emzirdiğini ve bu annelerin de \%63,4'ü bebeğini emzirmekte olduğunu belirtti. Bebeklerin sadece anne sütü alma süresi ise ortalama 4,56 ay olarak belirlendi (Tablo 1).

Annelerin \%75,8'i emzirme ve tamamlayıc beslenme ile ilgili bilgi aldığını ifade ederken, bilgi edinilen kaynaklarda \%38 ile "hemşire/ebe"nin ilk sırada yer aldığı görüldü. Tamamlayıcı besin seçiminde etkili olan faktörlerde de ilk sırada \%55 ile "sağlık personeli" yer almaktaydı (Tablo 2).

Tablo 2: Annelerin emzirme ve tamamlayıcı beslenme ile ilgili bilgi alma durumları.

\begin{tabular}{lcc}
\hline Özellikler & $\mathbf{n}$ & $\%$ \\
\hline $\begin{array}{l}\text { Emzirme ve tamamlayıcı beslenme hakkında bilgi } \\
\text { alma (n=380) }\end{array}$ & \\
$\quad$ Evet & 288 & 75,8 \\
$\quad$ Hayır & 92 & 24,2 \\
Bilginin elde edildiği kaynaklar (n=673)* & $* *$ \\
$\quad$ Hemşire/ebe & 256 & 38,0 \\
Kendi deneyimi & 200 & 29,7 \\
Broşür & 83 & 12,4 \\
$\quad$ Doktor & 79 & 11,7 \\
$\quad$ Yakın çevre & 26 & 3,9 \\
Dergi & 17 & 2,5 \\
Televizyon/radyo & 12 & 1,8 \\
Tamamlayıcı besin seçiminde etkili olan faktörler & & $* * *$ \\
(n=466)* & & \\
Sağlık personeli & 256 & 55,0 \\
İnternet ve televizyon & 132 & 28,3 \\
Yakın çevre ve aile büyükleri & 63 & 13,5 \\
Kitap ve dergi & 15 & 3,2 \\
\hline
\end{tabular}

*: Birden fazla seçenek işaretlendiği için $\mathrm{n}$ sayısı katlandı.

**: \% değerleri 673'e göre hesaplandı.

***: \% değerleri 466'ya göre hesaplandı. 
Tablo 3: Annelerin emzirme ve tamamlayıcı beslenme ile ilgili bilgi alma durumlarının annelerin bazı tanımlayıcı özelliklerine göre karşılaştırılması.

\begin{tabular}{|c|c|c|c|c|c|c|c|}
\hline \multirow{3}{*}{ Özellikler } & & \multicolumn{4}{|c|}{ Bilgi Alma Durumu } & \multirow{3}{*}{$x^{2}$} & \multirow{3}{*}{ p } \\
\hline & & \multicolumn{2}{|c|}{ Evet } & \multicolumn{2}{|c|}{ Hayır } & & \\
\hline & & $\mathbf{n}$ & $\%$ & $\mathrm{n}$ & $\%$ & & \\
\hline \multirow[t]{2}{*}{ Çalışma Durumu } & Çalışıyor & 48 & 85,7 & 8 & 14,3 & 3,526 & $0,060 *$ \\
\hline & Çalışmıyor & 240 & 74,1 & 84 & 25,9 & & \\
\hline \multirow[t]{2}{*}{ Meslek } & Diğer & 30 & 81,1 & 7 & 18,9 & 1,912 & $0,243^{*}$ \\
\hline & Sağlık çalışanı & 18 & 94,7 & 1 & 5,3 & & \\
\hline \multirow[t]{2}{*}{ Eğitim Durumu } & illköğretim ve altı & 110 & 69,2 & 49 & 30,8 & 6,504 & $0,011 *$ \\
\hline & Lise ve üzeri & 178 & 80,5 & 43 & 19,5 & & \\
\hline
\end{tabular}

*: Ki kare Testi

Annelerin emzirme ve tamamlayıcı beslenme ile ilgili bilgi alma durumlarının annelerin bazı tanımlayıcı özelliklere göre karşılaştırılmasında; annelerin çalışma durumu $(p=0,60)$ ve meslekleri $(p=0,243)$ ile bilgi alma durumları arasında anlamlı farklılık bulunmamaktaydı. Ancak, lise ve üzeri eğitim durumuna sahip olan annelerin bilgi alma durumlarının $(\% 80,5)$, ilköğretim ve alt eğitim durumundaki annelere $(\% 69,2)$ göre daha yüksek olduğu belirlenmiş olup bu farklılık istatistiksel olarak anlamlı bulundu $(p<0,05)$ (Tablo 3).

Bebeklerin beslenmesinden \%86,3 gibi büyük çoğunlukla annelerin sorumlu olduğu tespit edildi. Annelerin \%99,5'i tamamlayı$\mathrm{cı}$ besin vermeye geçtiklerini belirtirken, bu annelerin verdikleri tamamlayıcı besinde \%47,9 ile yoğurdun ilk tercih edilen besin olduğu görüldü. Annelerin \%55,3'ü tamamlayıcı besine geçiş sürecinde 3 gün bekleme kuralına uymadıklarını belirtti. Annelerin \%62,4'ü hazır mama yada kaşık mama, \%56,6'sı biberon, $\% 66,6$ 'sı ise emzik kullanmadıklarını ifade etti. Tamamlayıcı besinin hazırlanma şeklinde \%50,4 ile aile için hazırlanan aynı yemekler olduğu ve bebeğin beslenme şeklinde \%56 ile aile ile birlikte olduğu belirlendi (Tablo 4).

Annelerin bebeklerinde tamamlayıcı beslenmede bazı uygulamaların süre ortalaması incelendiğinde; tamamlayıcı beslenmeye başlama zamanı $(5,48 \pm 2,09)$, su verme zamanı $(3,95 \pm 2,52)$, çatal-kaşık kullanılma zamanı $(6,27 \pm 1,88)$ ve kat ve pürtüklü gıdaya başlanma zamanı $(7,02 \pm 1,84)$ ay olarak belirlendi.

Tamamlayıcı beslenmeye başlama zamanının anne ve bebeğe ait bazı tanımlayıcı özellikler ve annelerin uygulamalarına göre karşılaştırılmasında; gelir durumu, çocuk sayısı, bebeğin cinsiyeti, annenin bilgi alma durumu, annenin çalışma durumu, hemşire/ebeden ve doktordan bilgi alma durumu ile tamamlayıcı beslenmeye başlama zamanı arasında anlamlı farklııı bulunmamaktaydı $(p>0,05)$. Ayrıca, annenin yaşı ve tamamlayıcı beslenmeye başlama zamanı arasında da istatiksel olarak anlamlı bir ilişki saptanmadı $(p=0,514)$. Eğitim durumu $(p=0,000)$, biberon kullanımı $(p=0,000)$, emzik kullanımı $(p=0,001)$, formül mama $(p=0,000)$ ve kaşık mama kullanımı $(p=0,005)$ ile tamamlayıcı beslenmeye başlama zamanı arasında ise istatistiksel olarak anlamlı fark bulunmaktaydı (Tablo 5).
Tablo 4: Annelerin tamamlayıcı beslenme ile ilgili uygulamaları.

\begin{tabular}{lrc}
\hline Özellikler & $\mathbf{n}$ & $\%$ \\
\hline Bebeğin beslenmesinden sorumlu kişi $(\mathbf{n}=\mathbf{3 8 0})$ & & \\
$\quad$ Anne & 328 & 86,3 \\
Bakıcı & 29 & 7,6 \\
Baba/anane/babaanne & 23 & 6,1 \\
Tamamlayıcı besine başlama durumu ( $\mathbf{n}=\mathbf{3 8 0})$ & & \\
$\quad$ Evet & 378 & 99,5 \\
Hayır & 2 & 0,5 \\
Bebeğe ilk olarak verilen tamamlayıcı besin & & $* *$
\end{tabular}

$(n=378)^{*}$

$\begin{array}{lcc}\text { Yoğurt } & 181 & 47,9 \\ \text { Sebze ve meyve püresi } & 62 & 16,4 \\ \text { Mama } & 62 & 16,4 \\ \text { Çorba } & 52 & 13,8 \\ \text { Ekmek, bisküvi, kahvaltılık } & 13 & 3,4 \\ \text { Muhallebi } & 8 & 2,1\end{array}$

Tamamlayıcı besine geçiş sürecinde 3 gün

bekleme kuralını uygulama $(n=378) * *$

Evet

Hayır

Bebeğin hazır mama ya da kaşık mama kullanma durumu $(n=380)$

Evet

Hayır

Bebeğin biberon kullanma durumu $(n=380)$

Evet

Hayır

Bebeğin emzik kullanma durumu $(n=380)$

Evet

21556,6

Hayır

$127 \quad 33,4$

Tamamlayıcı besinin hazırlanma şekli $(n=423)^{* * *}$

Aile için hazırlanan aynı yemekler

$* * * *$

Bebek için hazırlanan ayrı yemekler

$213 \quad 50,4$

21049,6

Bebeğin beslenme şekli $(\mathrm{n}=439)^{* * *}$

$* * * * *$

Aile ile birlikte

24656,0

Ayrı zamanlarda

19344,0

*: Tamamlayıcı beslenmeye geçmeyen biri 7 aylık, diğeri 8 aylık olan 2 bebek analiz dışı bırakıldı.

**: \% değerleri 378 'e göre hesaplandı.

***: Birden fazla seçenek işaretlendiği için n sayısı katlandı.

$* * * *$ : \% değerleri 423'e göre hesaplandı.

$* * * * *$ : \% değerleri 439'a göre hesaplandı. 
Tablo 5: Tamamlayıcı beslenmeye başlama zamanının anne ve bebeğe ait bazı tanımlayıcı özellikler ve annelerin uygulamalarına göre karşılaştırılması.

\begin{tabular}{|c|c|c|c|c|c|}
\hline \multirow{2}{*}{ Özellikler } & & \multicolumn{4}{|c|}{ Tamamlayıcı beslenmeye başlama zamanı } \\
\hline & & Ort. & SS & $\mathrm{F} / \mathrm{t}$ & p \\
\hline \multirow[t]{5}{*}{ Eğitim durumu } & Sadece okuryazar & 8,60 & 4,088 & 6,505 & $0,000 *$ \\
\hline & ìlkokul & 5,29 & 2,179 & & \\
\hline & Ortaokul & 5,26 & 2,273 & & \\
\hline & Lise & 5,35 & 1,951 & & \\
\hline & Üniversite ve üzeri & 5,62 & 1,482 & & \\
\hline \multirow[t]{3}{*}{ Gelir durumu } & Gelir giderden az & 5,26 & 2,104 & 0,233 & $0,792^{*}$ \\
\hline & Gelir gidere denk & 5,46 & 2,076 & & \\
\hline & Gelir giderden fazla & 5,59 & 2,149 & & \\
\hline \multirow[t]{2}{*}{ Çocuk Sayısı } & Tek çocuk & 5,53 & 2,016 & 0,391 & $0,696 * *$ \\
\hline & Birden fazla çocuk & 5,45 & 2,143 & & \\
\hline \multirow[t]{2}{*}{ Bebeğin cinsiyeti } & $\mathrm{K} ı \mathrm{Z}$ & 5,38 & 2,265 & $-0,913$ & $0,362 * *$ \\
\hline & Erkek & 5,58 & 1,924 & & \\
\hline \multirow[t]{2}{*}{ Biberon kullanımı } & Evet & 4,96 & 2,450 & $-4,136$ & $0,000 * *$ \\
\hline & Hayır & 5,88 & 1,660 & & \\
\hline \multirow[t]{2}{*}{ Emzik kullanımı } & Evet & 4,91 & 2,526 & $-3,416$ & $0,001 * *$ \\
\hline & Hayır & 5,76 & 1,769 & & \\
\hline \multirow[t]{2}{*}{ Formül mama kullanımı } & Evet & 4,67 & 2,701 & $-5,347$ & $0,000 * *$ \\
\hline & Hayır & 5,97 & 1,405 & & \\
\hline \multirow[t]{2}{*}{ Kaşık mama kullanımı } & Evet & 5,08 & 2,453 & $-2,846$ & $0,005^{* *}$ \\
\hline & Hayır & 5,74 & 1,782 & & \\
\hline \multirow[t]{2}{*}{ Annenin bilgi alma durumu } & Evet & 5,40 & 1,920 & $-1,303$ & $0,194 * *$ \\
\hline & Hayır & 5,73 & 2,547 & & \\
\hline \multirow[t]{2}{*}{ Annenin çalışma durumu } & Çalışıyor & 5,68 & 1,642 & 0,764 & $0,445^{* *}$ \\
\hline & Çalışmıyor & 5,45 & 2,160 & & \\
\hline \multirow[t]{2}{*}{ Hemşire/ebeden bilgi alma } & Evet & 5,44 & 2,108 & $-0,618$ & $0,537^{* *}$ \\
\hline & Hayır & 5,58 & 2,061 & & \\
\hline \multirow[t]{3}{*}{ Doktordan bilgi alma } & Evet & 5,19 & 2,769 & $-1,118$ & $0,266^{* *}$ \\
\hline & Hayır & 5,56 & 1,870 & & \\
\hline & & \multicolumn{2}{|c|}{$r$} & \multicolumn{2}{|c|}{$p$} \\
\hline
\end{tabular}

Ort: ortalama, SS: standart sapma

*: Tek yönlü varyans analizi (One Way ANOVA)

**: Bağımsız Örneklem T Testi

***: Pearson Korelasyon Analizi

\section{TARTIŞMA}

Tamamlayıcı beslenme uygulamalarını doğrudan etkileyen annelerin emzirme durumları sorgulandığında; çalışmamızda annelerin büyük bir çoğunluğunun $(\% 99,2)$ bebeğini bir süre emzirdiği saptandı. TNSA (2018) verilerine göre Türkiye'de bu oranın \%98 (en az bir kere emziren) olduğu bildirilmiştir (12). Ülkemizde yapılan bir çalışmada ise bu oran \%95,6 olarak belirlenmiştir (17). Avrupa'da emzirme oranlarının incelendiği bir çalışmada; 11 Avrupa ülkesinin oranlarının farklılık gösterdiği ve bir süre emzirme oranlarının \%56 ile \%98 arasında değiştiği belirlenmiştir (18). ABD Hastalık Kontrol ve Önleme Merkezi [Centers for Disease Control and Prevention (CDC)]'nin 2020 yılı yılında yayınladığı raporda; bu oran $\% 84,1$ olarak belirlenmiştir (19). Çalışmamızda bir süre emzirme oranının ülkemizdeki emzirme oranları ile benzer olduğu, diğer ülkelerde ise bu oranın daha düşük olduğu görülmektedir. Bu doğrultuda ülkemizde emzirmenin daha yaygın olduğu söylenebilir. Ancak, çalışmada bebeklerin sadece anne sütü alma süresine bakıldığında bunun ortalama 4,5 ay olduğu görüldü. TNSA (2018) verilerine göre 
ise 3,6 ay olarak saptanmıştır (12). Çalışmamızda bebeklerin sadece anne sütü alma süresi Türkiye ortalamasının üzerinde olmasına rağmen, anne sütü alımının ve emzirmeye devam etme süresinin istenilen düzeyde olmadığı görülmektedir. Bu sonuç, çalışmadaki annelerin tamamlayıcı beslenme konusunda yeterli bilgiye sahip olmayarak emzirmeyi sonlandırma eğiliminde olduklarını düşündürmektedir.

Çalışmada annelerin çoğunluğunun $(\% 75,8)$ emzirme ve tamamlayıcı beslenme ile ilgili bilgi aldığı belirlendi. Yılmaz'ın (2019) 0-24 aylık bebeği olan annelerde yaptığı çalışmada; çalışmamızdaki orana benzer şekilde annelerin anne sütü ve ek gıda ile ilgili bilgi aldığı belirlenmiştir (20). Ancak bu çalışmada bilgi elde edilen kaynaklarda akraba ve yakın çevre ilk sırada yer alırken, bizim çaIışmamızda tamamlayıcı besin seçiminde en çok etkili olan faktör sağlık personeli olurken, hemşire ve ebelerin bilgi elde edinilen kaynaklarda ilk sırada yer aldığı görülmüştür. Ulusal ve uluslararası literatürde emzirme ve tamamlayıcı beslenme konusunda çalışmalar olmasına rağmen, çoğunlukla annelerin anne sütü ve emzirme ile ilgili bilgi alma durumlarına ait veriler bulunmaktadır (21-24). Oysaki tamamlayıcı beslenme uygulamaları anne sütü ve emzirmeden ayrı bir beslenme şekli olarak düşünülemez. Çünkü zamanında başlamayan ve uygun bir şekilde yürütülmeyen tamamlayıc beslenme uygulamaları bebeklerin anne sütü alımını azaltırken, emzirmenin erken dönemde sonlanmasına neden olabilir (15). Bu nedenle, tamamlayıcı beslenme konusunda annelerin alacakları herhangi bir eğitim, anne sütü alma süresini ve emzirmeyi de olumlu etkileyebilecektir. Şahin ve ark.'nın (2020) yaptıkları çalışmada tamamlayıcı beslenme konusunda eğitim verilen annelerin tamamlayıc beslenmeye 6 . ayda başlama oranlarının kontrol grubuna göre anlamlı derecede daha yüksek olduğu bildirilmiştir (7). Ayrıca çalışmada, eğitim durumu lise ve üzeri olan annelerin, emzirme ve tamamlayıcı beslenme konusunda eğitim alma durumunun diğer annelere göre anlamlı derecede yüksek olduğu görüldü. Bu sonuç, annelerin eğitim durumu yükseldikçe, bilgi edinecekleri kaynakları daha iyi sorgulamaları ve bilgiye daha kolay ulaşabilir olmaları ile açıklanabilir.

Çalışmadaki annelerden ikisi hariç hepsinin tamamlayıcı beslenmeye geçtiği görülmüştür. Tamamlayıcı beslenmeye geçen annelerin yarıya yakınının bebeklerine tamamlayıcı besin olarak ilk verdikleri gıda yoğurt olmuş, bunu meyve püresi ve mama takip etmiştir. Türkiye'de yapılan diğer çalışmalarda da çalışmamızdaki oranlara benzer şekilde tercih edilen ilk gıda yoğurt olmuştur (25-27). Etiyopya'da yapılan bir çalışmada, bebeklere ilk tamamlayıcı besin olarak tahıl ve bakliyat verildiği bildirilmiştir (28). Doğu Afrika ülkesi olan Malavi'de de 6-24. ayındaki bebeklerin büyük oranda tahıl ile beslendiği, çok az sayıda çocuğun süt ürünleri ile beslendiği ortaya konmuştur (6). Değişik ülkelerde anne sütünden sonra bebeklere verilen tamamlayıcı besinlerin incelendiği başka bir çalışmada da; Maldivler, Sri Lanka, Nepal, Hindistan'da bebeklerin büyük oranda tahıldan yapılan yerel besinler ile beslendiği bildirilmiştir (29). Brezilya'da yapılan bir çalışmada; annelerin yaşamın ilk ayından itibaren bebeklerini diğer hayvansal sütler ve tahıl grubu ile tanıştırdıkları ortaya konmuştur (30). Çalışmanın bulguları ülkemizdeki çalışmalar ile benzerlik gösterirken diğer ülkelerde yapılan çalışmalar ile farkIılık göstermektedir. Bunun nedeni olarak; ülkelerde yetiştirilen yerel ürün, yemek kültürü, din, etnik köken, gelenek ve görenek farklılığından kaynaklandığı düşünülmektedir.

Tamamlayıcı beslenme süresinde bebeklerde herhangi bir alerjik reaksiyon ya da besin intoleransını en aza indirmek için yeni besinler yavaşça tanıtımalıdır. Amerikan Pediatri Akademisi (AAP) ve Hastalık Kontrol ve Önleme Merkezi (CDC) tamamlayıcı beslenmeye geçişte, bir seferde tek bileşenli gıdanın verilmesini ve alerjik reaksiyonların izlenmesi için her yeni besinin sunulması arasında ortalama 3-5 gün beklenilmesini önermektedir (31).

Ülkemizde de tamamlayıcı beslenme uygulamalarında her yeni gıdanın teker teker en az 2-3 gün aralıklarla eklenmesi gerektiği önerilmektedir (7,32). Çalışmamızda ise annelerin sadece yarıya yakınının üç gün bekleme kuralını uyguladığı görülmüştür.

Çalışmada tamamlayıcı beslenmeye başlama zamanı ortalama 5 ay olarak bulunmuş, hatta bebeklere su verilme zamanın daha da erken olduğu ortalama 4 ay olduğu görülmüştür. TNSA (2018) verilerine göre ülkemiz geneli için bebeklere su verme oranı da çalışmamıza benzer şekilde 3,6 ay olarak belirlenmiştir (12). Tamamlayıcı beslenmeye başlama zaman ortalamalarına bakıldığında ise ülkemizde yapılan bir çalışmada 4,6 ay olarak belirlenmiştir (33). İran'da yapılan bir çalışmada tamamlayıcı beslenmeye başlama ortalama yaşı 5,5 ay olarak bulunmuştur (8). Çalışmamızda tamamlayıcı beslenmeye başlama zamanı ortalaması istenilen seviyede değildir ve bebeklere su verme zamanının çok daha erken aylarda olması da olumsuz bir sonuç olarak yorumlanabilir. Bu sonuç bize çalışmaya katılan annelerin emzirme ve tamamlayıcı beslenme konusundaki bilgi seviyelerinin yeterli olmadığını düşündürülebilir. Ayrıca çalışmada, eğitim durumu en az ilkokul olan anneler olmak üzere tüm annelerin tamamlayıcı beslenmeye çok erken başladığı görülürken, herhangi bir eğitimi olmayıp sadece okur-yazar olan annelerin ise tamamlayıcı beslenmeye çok geç başladığı (ortalama 8,6 ay) görülmüştür. Tamamlayıcı beslenmeye erken dönemde başlamak kadar geç dönemde başlamanın da bebeğin sağlığını olumsuz etkilediği düşünüldüğünde bu sonuç da annelerin tamamlayıcı beslenme konusundaki yetersiz bilgileri olduğunu destekler niteliktedir.

Tamamlayıcı beslenmede önemli uygulamalardan birisi de kat ve pürtüklü besinlerin bebeğin beslenmesine eklenmesi sürecidir. Kat besinleri bebeğin beslenmesine dahil etme, bebeğin gelişimi ve uygun beslenme alışkanlığı kazanması açısından önemlidir (13). Kat ve pürtüklü gıdaların en geç 8-10 aylıkken bebek beslenmesine eklenmesi, bu sürenin uzamasının ise bebeklerde beslenme güçlüğü riskini arttırdığı bildirilmiştir (32). Çalışmamızda ise annelerin ortalama 7. ayda katı ve pürtüklü besine geçtikleri belirlenmiş olup, bu literatür bilgisi doğrultusunda olumlu bir sonuç olarak yorumlanabilir.

Çalışmada annelerin bazı tanımlayıcı özelliklerinin ve uygulamalarının tamamlayıcı beslenmeye başlama zamanını etkilediği görülmüştür. Özellikle biberon, emzik, formül ve kaşık mama kullanan annelerde tamamlayıcı beslenmeye başlama zamanının bunları kullanmayan annelere göre anlamlı şekilde daha erken aylarda olduğu belirlenmiştir. Oysaki DSÖ, herhangi bir yaş grubu bebek ve çocuklar için biberon ve emzik kullanılmasından 
kaçınmak gerektiğini belirtmekte, tamamlayıc beslenmeye geçiş döneminde de fincan ve kaşık kullanımını önermektedir (10). Ulusal ve uluslararası yapılan çalışmalarda da biberon ve emzik kullanımının emzirme süresini kısalttğı ve tamamlayıcı beslenmeye geçiş sürecini hızlandırdığı ortaya konulmuştur (34-36). Çalışmada dikkat çeken başka bir bulgu ise; annenin emzirme ve tamamlayıcı beslenme hakkında bilgi almasının, bilgi aldığı kişinin sağlık profesyoneli olmasının, tamamlayıcı beslenmeye başlama zamanını etkilemediği görülmüştür. Bu sonuç bize; annelere verilen eğitimin yanında eğitimin içeriğinin de çok önemli olduğu, annelerin gereksinimleri doğrultusunda eğitim içeriğinin de yapılandırılması gerektiğini akla getirmektedir.

\section{SONUÇ}

Çalışmadan elde edilen bulgular, annelerin tamamlayıcı beslenme konusundaki bilgi durumlarının yeterli olmadığını, tamamlayıcı beslenme sürecini olumsuz etkileyebilecek bazı yanlış uygulamaları olduğunu göstermektedir. Ayrıca annenin eğitim durumunun tamamlayıcı beslenme konusunda bilgi alma durumunu ve tamamlayıcı beslenmeye başlama zamanını etkilediği belirlendi. Annelerin biberon, emzik formül ve kaşık mama kullanımının tamamlayıcı beslenmeye geçiş sürecini ise olumsuz etkilediği sonucuna varıldı.

Sonuç olarak, emzirmenin tamamlayıcı beslenme uygulamalarını doğrudan etkilediği görülmektedir. Bu nedenle anneler doğumdan itibaren ilk alth ay bebeklerine sadece anne sütü vermesi konusunda teşvik edilmelidir. Bunun için hamile ve doğum yapan annelere anne sütü ve emzirme konusundaki eğitimlerin verilmesi önerilir. Ayrıca bu eğitimler ile birlikte tamamlayıcı beslenme konusunda verilecek eğitimlerin de yaygınlaştıııması özellikle bu eğitimleri verecek kişilerin sağlık profesyonelleri olması önerilir. Verilecek eğitimlerin içeriklerinin ise annelerin gereksinimleri doğrultusunda düzenlenmesi ve sürekliliğinin sağlanması için tekrarlanması önerilir.

Etik Komite Onayı: Bu çalışma için etik kurul onayı Karabük Üniversitesi Girişimsel Olmayan Etik Kurulu'ndan alınmıştı (Tarih: 05.02.2019, No: 77192459-050.99-E.5689)

Bilgilendirilmiş Onam: Katılımcılardan bilgilendirilmiş onam alınmıştır.

Hakem Değerlendirmesi: Dış bağımsız.

Yazar Katkıları: Çalışma Konsepti/Tasarım- Ö.Ö.Ş., B.U.; Veri ToplamaB.U.; Veri Analizi/Yorumlama- Ö.Ö.Ş., B.U.; Yazı Taslağı- Ö.Ö.Ş., B.U.; İçeriğin Eleştirel İncelemesi- Ö.Ö.Ş..; Son Onay ve Sorumluluk- Ö.Ö.Ş., B.U.

Çıkar Çatışması: Yazarlar çıkar çatı̧̧ması beyan etmemişlerdir.

Finansal Destek: Yazarlar finansal destek beyan etmemişlerdir.

Ethics Committee Approval: This study was approved by Karabuk University Non-Interventional Ethics Committee. (Date: 05.02.2019, No: 77192459-050.99-E.5689)
Informed Consent: Written consent was obtained from the participants.

Peer Review: Externally peer-reviewed.

Author Contributions: Conception/Design of Study- Ö.ö.Ş., B.U.; Data Acquisition- B.U.; Data Analysis/Interpretation- Ö.Ö.Ş., B.U.; Drafting Manuscript- Ö.Ö.Ş., B.U.; Critical Revision of Manuscript- Ö.ö.Ş.; Final Approval and Accountability- Ö.Ö.Ş., B.U.

Conflict of Interest: Authors declared no conflict of interest.

Financial Disclosure: Authors declared no financial support.

\section{KAYNAKLAR/REFERENCES}

1. Yasmeen T, Kumar S, Sinha S, Hague MA, Singh V, Sinha S. Benefits of breastfeeding for early growth and long term obesity: a summarized review. IJMSDR 2019;3(1):190-4.

2. Gümüştakım RŞ, Aksoy HD, Cebeci SE, Kanuncu S, Çakır L, Yavuz E. 0-2 yaş çocuklarda beslenme alışkanlıklarının değerlendirilmesi: Çok merkezli çalışma. Fam Pract Palliat Care 2017;2(1):1-8. doi: 10.22391/920.308548

3. Alvisi P, Brusa S, Alboresi S, Amarri S, Bottau P, Cavagni C, et al. Recommendations on complemantary feeding for healthy, full-term infants. Ital J Pediatr 2015;41(1):1-9. doi: 10.1186/s13052-015-0143-5

4. Fewtrell M, Bronsky J, Campoy C, Domellöf M, Embleton N, Mis NF, et al. Complementary feeding: a position paper by the European Society for Paediatric Gastroenterology, Hepatology, and Nutrition (ESPGHAN) committee on nutrition. J Pediatr Gastroenterol Nutr 2017;64(1):119-32. doi: 10.1097/MPG.0000000000001454

5. Briaux J, Fortin S, Kameli Y, Agboka Y, Romedenne M, Boko J, et al., Dissimilarities across age groups in the associations between complementary feeding practices and child growth: Evidence from rural Togo. Matern Child Nutr 2019;15(4):e12843. doi: 10.1111/ mcn.12843

6. Nkoka O, Mhone TG, Ntenda PA. Factors associated with complementary feeding practices among children aged 6-23 mo in Malawi: an analysis of the demographic and health survey 20152016. Int Health 2018;10(6): 466-79. doi: 10.1093/inthealth/ihy047

7. Şahin GA, Kaya N, Kondolot $M$. Annelere verilen eğitimin tamamlayıcı beslenme üzerine etkisi. Bes Diy Derg 2020;48(1):1019. doi: 10.33076/2020.BDD.1257

8. Anbari K, Tajabadi Z, Baharvand P, Bazvand M, Khodadadi B. Evaluating infant complementary feeding pattern and some related factors in health care centers of khorramabad, West of Iran, in 2017. Epidemiol Biostat Public Health 2018;15(2):e12831-8. doi: $10.2427 / 12831$

9. Campoy C, Campos D, Cerdo T, Diequez E, Garcia-Santos JA. Complementary feding in developed countries: the $3 \mathrm{Ws}$ (When, What, and Why? Ann Nutr Metab 2018;73 (suppl 1):27-36. doi: $10.1159 / 000490086$

10. Worl Health Organization (WHO).10 Facts on breastfeeding. 2015. Erişim: http://www.who.int/features/factfiles/breastfeeding/facts/ en/index9.html. Son Erişim Tarihi: 17.12.2020

11. World Health Organization (WHO). Global breastfeeding scorecard, 2018 enabling women breastfeed through better policies and programmes. Erişim: https://www.who.int/nutrition/publications/ infantfeeding/global-bf-scorecard-2018.pdf?ua=1. Son Erişim Tarihi: 17.12 .2020 
12. Türkiye Nüfus Sağlık Araştırması (TNSA). Türkiye nüfus ve sağlık araştırması 2018. Erişim: http://www.hips.hacettepe.edu.tr/ tnsa2018/rapor/TNSA2018_ana_Rapor.pdf Son Erişim Tarihi: 08.01.2021

13. Komninou S, Halford JCG, Harrold JA. Differences in parental feeding styles and practices and toddler eating behaviour across complementary feeding methods: Managing expectations through consideration of effect size. Appetite 2019;137(1):198-206. doi: 10.1016/j.appet.2019.03.001

14. Liotta N, Cresi F, Beghetti I, Roggero P, Menis C, Corvaglia L, et al. Complementary feding in preterm infants: A systematic review. Nutrients 2020;12(6):1843. doi: 10.3390/nu12061843

15. Palombo CNT, Fujimori E, Toriyama ÁTM, Duarte LS. (2018) Training in nutritional counseling: knowledge assessment and applicability in child's healthcare. Rev Bras Saude Mater Infant 2018;18(1):6774. doi: 10.1590/1806-93042018000100003

16. Cangöl E, Sahin NH. Emzirmenin desteklenmesinde bir model: Pender'in Sağlığı Geliştirme Modeline dayalı motivasyonel görüşmeler. Koç Universitesi Hemşirelikte Eğitim ve Araştırma Dergisi (HEAD) 2017;14(1):98-103. doi: 10.5222/HEAD.2017.098

17. Öztürk Ö, Sarıkaya P, Özdemir Ş, Çikendin Z, Zünbül N. Anne sütü ve emzirme ile ilgili anneler tarafindan bilinen doğrular ve yanlışlar. JCP 2018;16(2):40-54.

18. Theurich MA, Dvanzo R, Busck-Rasmussen M, Diaz-Gomez NM, Brennan C, Kylberg E, et al. Breastfeeding rates and programs in Europe: a survey of 11 National Breastfeeding Committees and representatives. JPGN 2019;68(3):400-407.

19. Centers for Disease Control and Prevention (CDC). Breastfeeding report card United States, 2020. Erişim: https://www.cdc.gov/ breastfeeding/pdf/2020-Breastfeeding-Report-Card-H.pdf. Son Erişim Tarihi: 08.01.2021

20. Yılmaz G. 0-24 aylık bebeklerin beslenme şekillerinin incelenmesi. Gümüşhane Üniversitesi Sağlık Bilimleri Dergisi 2019;8(4):343-52.

21. Şahin BB, Özyurt BC. Manisa'da yarı-kentsel bir bölgede 0-24 ay çocuklarda anne sütü alma durumu ve beslenme alışkanlıkları. Turk J Public Health 2017;15(3):164-75.

22. Kaya Z, Yiğit Ö, Erol M, Gayret ÖB. Altı-yirmi dört ay arası yaş grubunda beslenmeyle ilgili anne ve babaların bilgi ve deneyimlerinin değerlendirilmesi. Med Bull Haseki 2016;54:70-5. doi: 10.4274/haseki.2756

23. Parry KC, Tully KP, Hopper LN, Schildkamp PE, Labbok MH. Evaluation of ready, set, baby: a prenatal breastfeeding education and counseling approach. Birth 2019;46(1):113-120. doi: 10.1111/ birt.12393

24. Iliadou M, Lykeridou K, Prezerakos P, Swift EM, Tziaferi SG. Measuring the effectiveness of a midwife-led education programme in terms of breastfeeding knowledge and selfefficacy, attitudes towards breastfeeding, and perceived barriers of breastfeeding among pregnant women. Mater Sociomed 2018;30(4):250-245. doi: 10.5455/msm.2018.30.240-245
25. Kumru B, Karakoyun M. Assessment of malnutrition and nutritional status of hospitalized and treated children aged between 12 and 60 months. Eur J Ther 2018;24:30-5. doi: 10.5152/EurJTher.2017.143

26. Kolsuz S, Saka G, Gördük MN. Diyarbakır Benusen'de 0-5 yaş çocuklarda malnütrisyon prevalansı ve ilişkili faktörler. Turk J Public Health 2019;17(1):65-78. doi: 10.20518/tjph.386079

27. Altınbaş Z, Güldemir HH, Garipoğlu M. Alth-12 aylık bebeklerin beslenme ve büyüme-gelişme durumlarının değerlendirilmesi. J Child 2020;20(1):13-19. doi: 10.26650/jchild.2020.1.003

28. Dagne AH, Anteneh KT, Badi MB, Adhanu HH, Ahunie MA, Tebeje $H D$, et al. Appropriate complementary feeding practice and associated factors among mothers having children aged 6-24 months in Debre Tabor Hospital, North West Ethiopia, 2016. BMC Res Notes 2019;12:215. doi: 10.1186/s13104-019-4259-3

29. Aguayo VM. Complementary feeding practices for infants and young children in South Asia. A review of evidence for action post-2015. Matern Child Nutr 2017;13(S2):e12439. doi: 10.1111/ mcn.12439

30. Maciel BLL, Moraes ML, Soares AM, Cruz IFS, de Andrade MIR, Junior FS, et al. Infant feeding practices and determinant variables for early complementary feeding in the first 8 months of life: results from the Brazilian MAL-ED cohort site. 2018;21(13):246270. doi: 10.1017/S136898001800099X

31. Samady W, Campbell E, Aktas ON, Jiang J, Bozen A, Fierstein JL, et al. Recommendations on complementary food introduction among peadiatric practitioners. JAMA Netw Open 2020;3(8):e2013070. doi: 10.1001/jamanetworkopen.2020.13070

32. Yazıcı B. Tamamlayıcı beslenme. Klinik Tıp Pediatri Dergisi 2018;10(1):7-16.

33. Şatır G, Çelik M, Kemhacıoğlu M. Emzirme döneminde olan annelerin bebek besleme alışkanlıkları ve bunları etkileyen faktörler. SDÜ Tıp Fak Derg 2017;24(3):60-6. doi: 10.17343/ sdutfd. 277492

34. Bezerra VM, Magalhães EIS, Pereira IN, Gomes AT, Netto MP, Rocha DS. Prevalence and determinants of the use of pacifiers and feedingbottle: a study in Southwest Bahia. Rev Bras Saude Mater Infant 2019;19(2):311-21. doi: 10.1590/1806-93042019000200004

35. Hoff CE, Movva N, Rosen Vollmar AK, Pérez-Escamilla R. Impact of maternal anxiety on breastfeeding outcomes: a systematic review. Adv Nutr 2019;10(5):816-26. doi: 10.1093/advances/nmy132

36. Uğurlu ES, Çakal MM, Avşar A. Annelerin 0-1 yaş arası bebeklerinde emzik kullanma durumları. ACU Sağlık Bil Derg 2017;1:10-5. 